\title{
Parathyroid carcinoma as a challenging diagnosis: Report of three cases
}

\author{
Alfredo Campenni*, ${ }^{1}$ Rosaria Maddalena Ruggeri*, ${ }^{2}$ Alessandro Sindoni, ${ }^{1}$ \\ Salvatore Giovinazzo, ${ }^{2}$ Letterio Calbo, ${ }^{3}$ Antonio Ieni, ${ }^{4}$ Maurizio Monaco, ${ }^{5}$ \\ Giovanni Tuccari, ${ }^{4}$ Salvatore Benvenga, ${ }^{2,6}$ Sergio Baldari ${ }^{1}$
}

${ }^{1}$ Department of Radiological Sciences, Nuclear Medicine Unit, ${ }^{2}$ Department of Clinical and Experimental Medicine and Pharmacology, Section of Endocrinology, ${ }^{3}$ Department of Human Pathology, Section of Surgery, ${ }^{4}$ Department of Human Pathology \& ${ }^{5}$ Cardiovascular and Thoracic Department, University of Messina, ${ }^{6}$ Program of Molecular and Clinical Endocrinology and Women's Health, A.O.U. Policlinico G. Martino, Messina, Italy

*The first two authors contributed equally to this study

\begin{abstract}
Parathyroid carcinoma (PC) is a rare malignancy with an indolent but progressive course. This rare tumour is often difficult to diagnose preoperatively, thus limiting the efficacy of surgery. As long-term survival is largely dependent on the extent of the primary surgical resection, it is of great importance to consider PC in the differential diagnosis of hyperparathyroidism. We herein report three PC patients with different clinical histories who were followed up at our hospital for over a 5-year period, emphasizing the variability in clinical presentation of this rare tumour. Moreover, NORA (Nucleolar Organizer Regions, a standardised silver-stain, marker of proliferation rate) values encountered in these PC patients confirm that AgNOR analysis may be regarded as an additional tool when the pathologist encounters difficulties in defining parathyroid lesions which are not clearly benign.
\end{abstract}

Key words: AgNOR, Hypercalcemia, Ki-67, Parathyroid carcinoma, Primary hyperparathyroidism

\section{INTRODUCTION}

Parathyroid carcinoma (PC) is an uncommon endocrine malignancy that accounts for $0.005 \%$ of

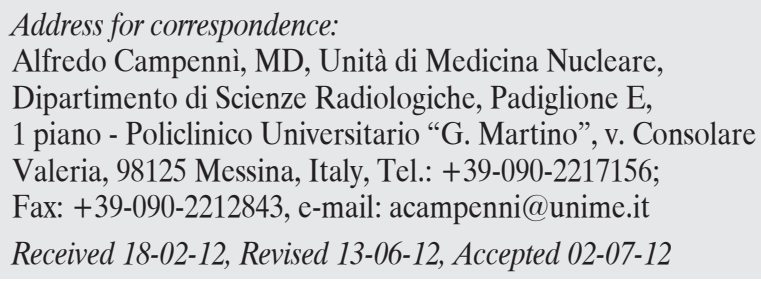

all cancers and about $1 \%$ of the cases of primary hyperparathyroidism. ${ }^{1-6}$ Patients with familial hyperparathyroidism, multiple endocrine neoplasia type 1 (MEN1) and a history of neck irradiation are at increased risk for developing this neoplasia. ${ }^{1-3} \mathrm{PC}$ occurs with equal frequency in both sexes (F:M ratio $=1: 1)$, in contrast with parathyroid adenomas $(\mathrm{F}: \mathrm{M}$ ratio 3-4:1); $\mathrm{PC}$ is usually diagnosed in the fifth decade, approximately ten years earlier than its benign counterpart. ${ }^{1-3}$ 
The typical features of $\mathrm{PC}$ are represented by signs and symptoms of severe hypercalcemia, with renal and bone involvement in up to $90 \%$ of patients. ${ }^{1-3}$ Clinical suspicion may be aroused when there is a palpable cervical mass with or without recurrent laryngeal nerve paralysis or hoarseness, when there are concomitant bone and renal manifestations and when serum levels of calcium and PTH are very high. ${ }^{1-3}$ In the cases reported in the literature, the tumour size ranges from 1 to $12 \mathrm{~cm}$, with a mean of $3 \mathrm{~cm} .{ }^{7}$ All the above features suggest malignancy but the differential diagnosis between benign and malignant disease is often difficult to determine on clinical grounds. Even the histology of PC can be equivocal or frankly misleading. ${ }^{3,8}$ Thus, commonly the diagnosis of PC is made a posteriori, when local recurrence or distant metastases occur. ${ }^{1-3}$

As better outcomes are associated with complete resection of the tumour at the time of initial surgery, the difficulty encountered by clinicians in diagnosing pre-operatively this rare tumour may limit the effectiveness of the surgical treatment. ${ }^{2,5,9}$ It has been demonstrated that under staging and under treatment of PC contributes to the high recurrence rates and mortality of the disease. ${ }^{69}$ En bloc resection of the carcinoma and the adjacent structures in the neck, including ipsilateral thyroid lobe and isthmus, lymph nodes and soft tissues, represents the treatment of choice. ${ }^{1-3,8,9}$ This surgical approach is associated with an $8 \%$ local recurrence rate and a long-term overall survival rate of $89 \% .{ }^{9}$ In contrast, simple parathyroidectomy results in a $51 \%$ local recurrence rate and 53\% long-term survival rate. Here we report three cases of PC observed at our University Hospital over a 5-year period. These cases highlight the variability in clinical presentation of PC and the need for individualized care. We also review the literature on clinical presentation, diagnosis and management of this rare entity, with the principal aim of outlining the features that help in distinguishing PC from parathyroid adenoma.

\section{PATIENTS}

Biochemical data of the three patients at admittance to our University Hospital are summarized in Table 1. Histopathological features of each case are summarized in Table 2. Illustrative images of each case are also provided.

\section{CASE 1}

Woman, aged 54 years. Two years earlier she had undergone near-total thyroidectomy because of a large, benign multinodular goiter. At the time of thyroidectomy, the surgeon did not find enlarged parathyroids, and post-operatively serum calcium levels were within normal levels. Biochemical followup disclosed modest hypercalcemia $(10.7 \mathrm{mg} / \mathrm{dL}$; normal values 8.2-10.4), which prompted PTH assay. As shown in Table 1, serum intact PTH was elevated ( $320 \mathrm{pg} / \mathrm{mL} ; \mathrm{nv} 12-62 \mathrm{pg} / \mathrm{ml}$ ), and the 24-hours urinary calcium was increased (345 mg/24h, nv 100-300). The patient complained of no bone pain, abdominal (constipation, gastritis) or renal symptoms (lithiasis). Her past medical history was significant for mild, and untreated, osteoporosis. Her bone mineral density (BMD), assessed by dual-energy x-ray absorptiometry (DEXA) at the lumbar spine and femoral neck and expressed as T-scores, was -2.6 at both sites. She denied having prior radiation exposure. The patient underwent neck ultrasonography (US) which revealed a 21-mm hypoechoic nodule with indistinct margins and multiple calcifications, in a position corresponding to the lower pole of the right thyroid lobe, suggesting a parathyroid mass. No abnormal lymph nodes were detected in the neck. Dual phase parathyroid scintigraphy with ${ }^{99 \mathrm{~m}} \mathrm{Tc}$-methoxyisobutylisonitrile ( $\left.{ }^{99 \mathrm{~m}} \mathrm{Tc}-\mathrm{MIBI}\right)$ showed an abnormal tracer uptake in the inferior parathyroid gland, in a position corresponding to the mass revealed at US (Figure 1). All findings were consistent with primary hyperparathyroidism and the patient underwent surgery. As detailed in Table 2, pathological examination of the excised mass revealed a parathyroid carcinoma (Figure 2, panel A). Via immunohistochemistry, a variously represented Ki-67 expression was evident in different neoplastic areas, even though the values of single labelling index (Ki-67 LI) observed in each field were never over $5 \%$. A value of 3.75 was recorded as mean Ki-67 LI (Table 2 and Figure 2, panel B). Moreover, to determine the proliferation rate, a standardised silver-stained Nucleolar Organizer Regions (AgNOR) analysis was also performed, as reported elsewhere. ${ }^{10}$ Mean NORA value was $4.287 \mu \mathrm{m}^{2}$ (Standard Error 0.168), 
Table 1. Serum and urinary biochemical data and normal ranges of our three patients at admittance ${ }^{a}$

\begin{tabular}{|c|c|c|c|c|}
\hline Analyte (unit of measure) & Case 1 & Case 2 & Case 3 & Normal ranges \\
\hline Total calcium (mg/dl) & 10.7 & 13.0 & 15.3 & $8.2-10.4$ \\
\hline Ionized calcemia (mmol/L) & 1.30 & 1.52 & 1.90 & $1.10-1.30$ \\
\hline Phosphorus (mg/dl & 2.6 & 2.2 & 3.1 & $2.5-4.6$ \\
\hline Magnesium (mg/dl) & 2.1 & 1.8 & 1.5 & $1.5-3.8$ \\
\hline Sodium (mmol/L) & 138 & 143 & 134 & $130-148$ \\
\hline Potassium (mmol/L) & 3.9 & 4.6 & 3.4 & $3.5-5.2$ \\
\hline Creatinine (mg/dl) & 0.5 & 0.6 & 2.2 & $0.5-1.4$ \\
\hline Urea nitrogen (mg/dl) & 25 & 39 & 84 & $10-50$ \\
\hline Total proteins g/dl & 6.9 & 7.6 & 5.8 & $6-8.2$ \\
\hline Alkaline phosphatase (U/L) & 133 & 522 & 274 & $0-270$ \\
\hline PTH $(\mathrm{pg} / \mathrm{ml})^{\mathrm{b}}$ & 320 & 899 & 1266 & $12-62$ \\
\hline Vitamin D (ng/ml) & 50.7 & 45.2 & 36.9 & $20-100$ \\
\hline 1, 25 OH-vitamin D (ng/ml) & 40.8 & 35 & 28 & $20-120$ \\
\hline Osteocalcin (ng/ml) & 10.60 & 22.90 & 21.4 & $1.60-17.4$ \\
\hline Calcitonin (pg/ml) & $<2.0$ & $<2.0$ & $<2.0$ & $0-12$ \\
\hline Chromogranin A (ng/ml) & 81 & 40 & 556 & $<100$ \\
\hline Neuron Specific Enolase (ng/ml) & 8.40 & 4.40 & 3.4 & $4-14.7$ \\
\hline Serum Carcinoembryogenic antigen $(\mu \mathrm{g} / \mathrm{L})$ & 0.6 & 1.2 & 2.1 & $0-5.0$ \\
\hline CA 19.9 & 7.0 & 37.6 & 2.5 & $0-40$ \\
\hline FT3 (pg/ml) & $3.8^{c}$ & 3.5 & 2.8 & $2-4.4$ \\
\hline FT4 (pg/ml) & $12.9^{c}$ & 14.3 & 11.7 & $9.4-17.2$ \\
\hline TSH (uIU/ml) & $2.0^{c}$ & 1.20 & 0.52 & $0.25-4.20$ \\
\hline Plasma epinephrine (pg/ml) & 45.3 & 15.7 & 23.7 & $10-80$ \\
\hline Plasma norepinephrine (pg/ml) & 318.8 & 114 & 288 & $95-548$ \\
\hline \multicolumn{5}{|l|}{ URINE } \\
\hline Creatinine clearance (ml/min) & 82.2 & 91.5 & - & $70-120$ \\
\hline Calcium (mg/24h) & 345 & 540 & - & $100-300$ \\
\hline Phosphorus (g/24h) & 1.0 & 3.1 & - & $0.8-1.0$ \\
\hline OH-proline (mg/24h) & 34.5 & 58 & - & $14-45$ \\
\hline Epinephrine $(\mu \mathrm{g} / 24 \mathrm{~h})$ & 15.2 & 3.4 & $5.30^{\mathrm{d}}$ & $1.7-22.4$ \\
\hline Norepinephrine $(\mu \mathrm{g} / 24 \mathrm{~h})$ & 60.4 & 69 & 50.90 & $12.1-85.5$ \\
\hline Metanephrine $(\mu \mathrm{g} / 24 \mathrm{~h})$ & 118.8 & 119.2 & 92.60 & $52-341$ \\
\hline Dopamine $(\mu \mathrm{g} / 24 \mathrm{~h})$ & 320 & 215 & 175 & $0-498$ \\
\hline
\end{tabular}

${ }^{a}$ Boldface values indicate abnormality. ${ }^{\mathrm{b}}$ Serum intact PTH was measured using a solid-phase, two-site chemiluminescent enzymelabeled immunometric assay (Immulite 2000). ${ }^{\mathrm{c}}$ under L-Thyroxine therapy (100 $\left.\mu \mathrm{g} / \mathrm{die}\right) .{ }^{\mathrm{d}}$ At time of admittance to our hospital, the patient had severe hydronephrosis and an ureteral stent. It was thus difficult to evaluate the urinary parameters on a $24 \mathrm{~h}$ sample. Urinary epinephrine, normetanephrine and metanephrine were determined afterwards.

a value similar to that reported in malignant parathyroid lesions ${ }^{10}$ (Figure 2, panel C). One of the excised lymph nodes was metastatic, while soft tissues were clear of tumour tissue. Serum calcium decreased to $8.4 \mathrm{mg} / \mathrm{dL}$ postoperatively. On the 6th post-operative day, the patient was discharged uneventfully with a 
Table 2. Histopathological features of the three parathyroid carcinomas

\begin{tabular}{|c|c|c|c|c|}
\hline Case no & Gross pathology & Histopatological evaluation ${ }^{a}$ & $\begin{array}{l}\text { Ki-67 } \\
\text { Labeling } \\
\text { Index }^{\mathrm{b}}\end{array}$ & Mean NORA value \\
\hline 1. & $\begin{array}{l}\text { A whitish and lobulated } \\
\text { parathyroid mass separated from } \\
\text { surrounding tissues by a fibrous } \\
\text { capsule. The mass measured } 2.2 \\
\text { x } 2 \mathrm{~cm} \text { with a weight of } 3 \mathrm{~g}\end{array}$ & $\begin{array}{l}\text { Neoplastic elements characterized by round } \\
\text { nuclei with prominent nucleoli were arranged } \\
\text { in solid and diffuse nodules. Thick, sharply } \\
\text { outlined bands of collagenous tissue were } \\
\text { projected from the capsule into the interior of } \\
\text { the mass, giving rise to irregular lobules. At } \\
\text { the periphery of the lesion, areas of capsular } \\
\text { invasion by neoplastic cells as well as neoplastic } \\
\text { thrombi inside vessels were detected (see } \\
\text { Figure 2, panel A). }\end{array}$ & 3.75 & $\begin{array}{l}4.287 \mu \mathrm{m}^{2} \\
\text { (Standard Error 0.168) } \\
\text { (See Figure 3, panel C) }\end{array}$ \\
\hline 2. & $\begin{array}{l}\text { Parathyroid mass of } 6 \times 5 \times 5.5 \\
\mathrm{~cm} \text {, surrounded by a grayish, } \\
\text { discontinuous capsule }\end{array}$ & $\begin{array}{l}\text { Neoplastic elements appeared uniform with } \\
\text { central hyperchromatic nuclei, occasional } \\
\text { prominent nucleoli and clear cytoplasm. They } \\
\text { were arranged in irregular lobules exhibiting } \\
\text { a trabecular pattern. At the periphery of the } \\
\text { lesion, areas of invasion of the thyroid as well as } \\
\text { soft tissues were detected. }\end{array}$ & 3.12 & $\begin{array}{l}4.425 \mu \mathrm{m}^{2} \\
\text { (Standard Error 0.113) }\end{array}$ \\
\hline 3. & $\begin{array}{l}\text { Intrathyroidal parathyroid mass } \\
\text { of } 3.5 \times 3 \times 3.5 \mathrm{~cm} \text { surrounded by } \\
\text { a dense fibrous capsule }\end{array}$ & $\begin{array}{l}\text { The neoplastic elements, arranged in } \\
\text { solid sheets with a cordonal pattern, were } \\
\text { monomorphous, with round to ovoid, enlarged } \\
\text { nuclei, frequently evident nucleoli and clearly } \\
\text { demarcated cytoplasms. The capsule appeared } \\
\text { discontinuous for the presence of proliferating } \\
\text { neoplastic solid cell nests. }\end{array}$ & 3.09 & $\begin{array}{l}4.735 \mu \mathrm{m}^{2} \\
\text { (Standard Error 0.201) }\end{array}$ \\
\hline
\end{tabular}

${ }^{a}$ Histopathological examination was carried out on formalin-fixed paraffin-embedded tissue blocks. ${ }^{\mathrm{b}}$ On $5 \mu$ parallel section, immunohistochemistry for Ki-67 antigen was performed using the monoclonal antibody MIB-1 (Dako Cytomation, Copenhagen, Denmark; working dilution 1:200), after an antigen retrieval pre-treatment by three cycles x 5 min (0.01 M citrate buffer, $\mathrm{pH} 6.0)$ in a microwave oven. The Ki-67 staining score was evaluated by counting the percentage of positive nuclei per 1000 neoplastic cells in up to 10 representative fields of the whole neoplastic portions; all degrees of nuclear staining intensity were taken into consideration. ${ }^{\mathrm{c}}$ Standardised silver-stained Nucleolar Organizer Regions (AgNOR) analysis was performed as reported elsewhere (see ref. 10), and the mean area (in square micrometres) of AgNORs per nucleus (NORA) was evaluated by means of an image analyser and specific softwares.

serum level of PTH of $5 \mathrm{pg} / \mathrm{mL}$ and calcemia of 8.2 $\mathrm{mg} / \mathrm{dL}$. The patient was followed up for five years, during which serum levels of calcium and PTH remained within the normal range with no recurrent disease detected at US, ${ }^{99 \mathrm{~m}} \mathrm{Tc}-\mathrm{MIBI}$ scintigraphy and contrasted-computed tomography (CT).

\section{CASE 2}

Woman, aged 54 years. Two years before, severe osteoporosis was discovered (DEXA T-scores of $-4.8 \mathrm{SD}$ at both the lumbar spine and femoral neck). $\mathrm{X}$-rays and CT scan of the spine showed diffuse osteoporosis and a vertebral compression fracture in the thoracolumbar junction (T10). Whole-body bone scintigraphy with $99 \mathrm{mTechnetium} \mathrm{methylene-}$ diphosphonate (99mTc-MDP) displayed an abnormal uptake in the T10 vertebral body, as well as a number of areas of increased activity in some ribs (fourth and fifth right ribs, and fourth left rib) and long bones (proximal right femur and upper tibiae). Medical therapy with bisphosphonates and vitamin D was started. The vertebral fracture was treated with percutaneous vertebroplasty (bone cement augmentation). In the following two years, the patient complained of progressive bone pain; both spinal and femoral BMD did not improve. Moreover, a new vertebral collapse occurred at T9, as detected at CT scan. The patient was referred to the Endocrinology Unit for suspected hyperparathyroidism. Biochemical data 


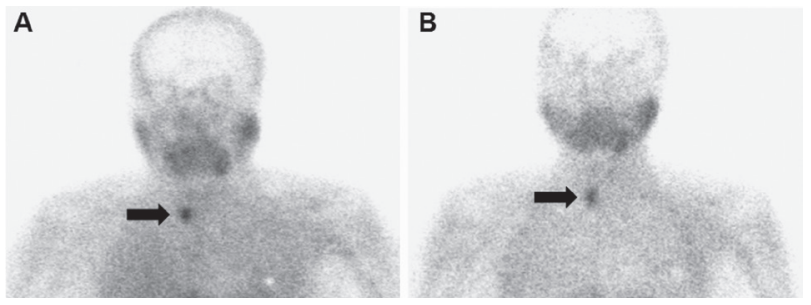

Figure 1. Case \#1. Dual phase parathyroid scintigraphy with 99mTc-MethoxyIsobutylIsonitrile (MIBI). Planar images of the neck and thoracic regions (10 minutes per frame) were acquired $10 \mathrm{~min}(\mathrm{~A})$ and $120 \mathrm{~min}(\mathrm{~B})$ after i.v. administration of $370 \mathrm{MBq}$ of ${ }^{99 \mathrm{~m}} \mathrm{Tc}-\mathrm{MIBI}$ (magnification 1 and 2, matrix $265 \times 256$ and $128 \times 128$, respectively). Images were obtained using a dualheaded gamma-camera equipped with low-energy high-resolution parallel-hole collimator (LEHRPAR). A photopeak of 140 $\mathrm{KeV}$ with symmetrical $20 \%$ window was used. A focal area of abnormal tracer uptake was appreciated next to the lower pole of the right thyroid (black arrow).

of the patient are summarized in Table 1. Neck US revealed the presence of a mixed-structure nodule of $39 \times 30 \times 20 \mathrm{~mm}$, with abnormal intranodular blood flow and multiple calcifications. The nodule was adjacent to the inferior pole of the right thyroid lobe, reaching the jugulum. CT scan showed a lesion of $50 \mathrm{~mm}$ in longitudinal diameter in the right side of the neck, which displayed substernal extension inferior to the level of the aortic arch. (Figure 3, panel A). Dualphase ${ }^{99 \mathrm{~m}}$ Tc-MIBI scan demonstrated an abnormal tracer uptake in the same location, corresponding to the inferior right parathyroid gland (Figure 3, panels
B and C). 18F-fluorodeoxyglucose positron emission tomography (18FDG-PET) total-body scanning was negative.

The patient underwent surgery through a cervical approach and a median sternotomy. Histopathological evaluation was consistent with PC (Table 2). As regards proliferation markers, the mean $\mathrm{Ki}-67 \mathrm{LI}$ was 3.12, while the mean NORA value was 4.425 $\mu \mathrm{m}^{2}$ (Standard Error 0.113) (Table 2). Serum calcium dropped to $7.7 \mathrm{mg} / \mathrm{dL}$ postoperatively, requiring calcium and calcitriol supplementation. On the 6th post-operative day, the patient was discharged uneventfully with a serum level of PTH of $24.5 \mathrm{pg} / \mathrm{mL}$ and calcium of $8.2 \mathrm{mg} / \mathrm{dL}$, under calcium therapy. Three months after surgery, the patient underwent neck US, ${ }^{99 \mathrm{~m}} \mathrm{Tc}-\mathrm{MIBI}$ scintigraphy and CT total body scan, all negative for persistence/recurrence of disease, and the doses of calcium and calcitriol were gradually reduced up to withdrawal. Both serum PTH and calcium levels have remained within normal levels during the subsequent 36 months' duration follow-up with no evidence of recurrent disease. Both spinal and femoral BMD significantly improved (T-score -2.6 and -2.4 , respectively, at the last control).

\section{CASE 3}

Woman, aged 75 years. Her past medical history included hypertension, mental depression, degenerative joint disease, diffuse osteoporosis of the spine
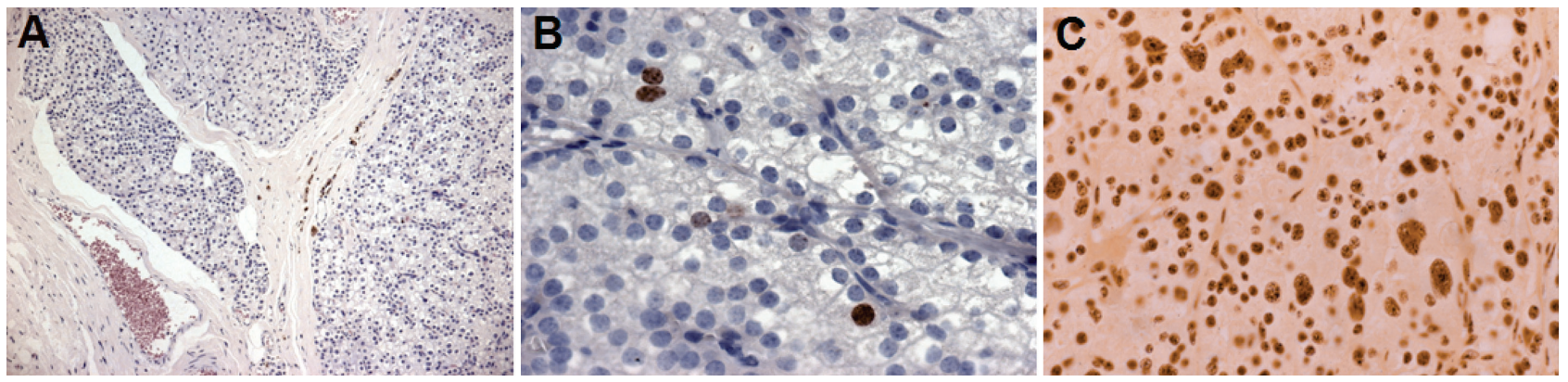

Figure 2. Case \#1. Histological features of the parathyroid lesion (magnification, $\times 150$ ). The neoplastic elements, characterized by round nuclei with prominent nucleoli, were arranged in diffuse masses or in solid sheets. At the periphery of the lesion, areas of capsular invasion by neoplastic cells as well as neoplastic thrombi inside vessels were also found. Nuclear immunostaining for MIB-1 (B, magnification x400). Nucleolar Organizer Regions (AgNOR) analysis. Neoplastic parathyroid showed an adequate homogeneous staining intensity throughout the whole section. In both nuclei and nucleoli of neoplastic cells, the AgNORs were clearly distinguishable as black dots. Moreover, an increase of extranucleolar silver dots scattered throughout the nucleus was found. Occasionally, the AgNORs were clustered in irregularly shaped collections inside carcinomatous cells (C, magnification $\times 400)$. 

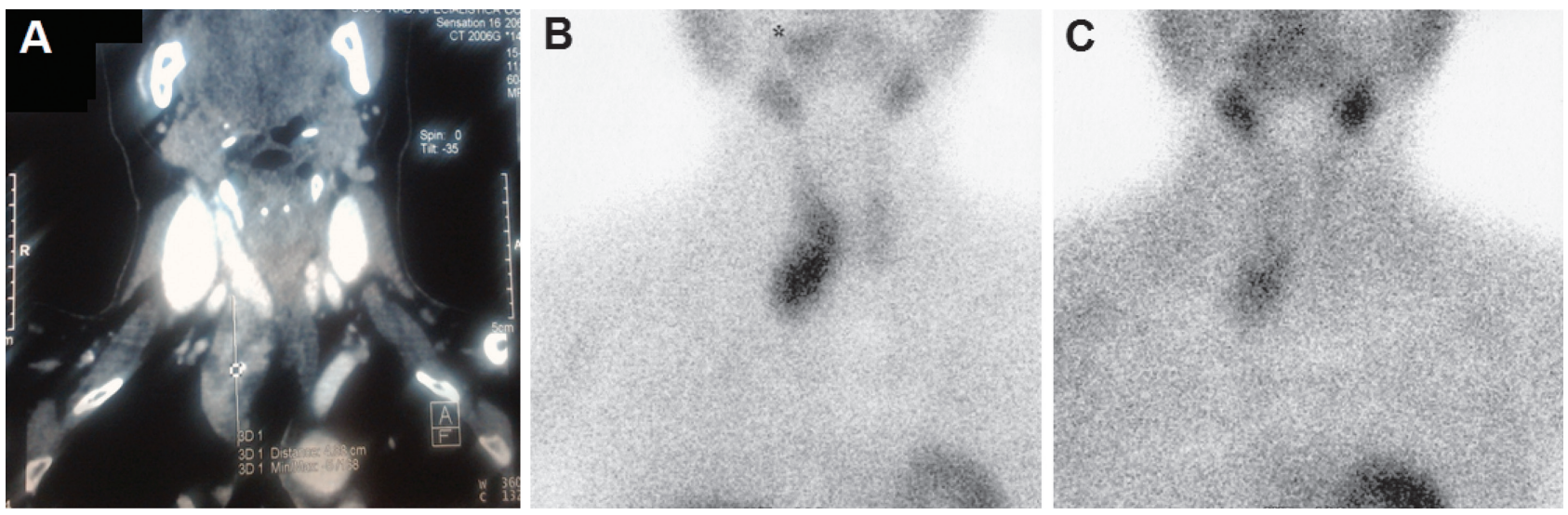

Figure 3. Case \#2. CT scan of neck and thorax, demonstrating the presence of a lesion of $50 \mathrm{~mm}$ in longitudinal diameter in the right side of the neck, which displayed substernal extension inferior to the level of the aortic arch (A). Dual phase parathyroid scintigraphy with ${ }^{99 \mathrm{~m}} \mathrm{Tc}-\mathrm{MIBI}$, demonstrating an abnormal tracer uptake in a location corresponding to the inferior right parathyroid gland (B, C).
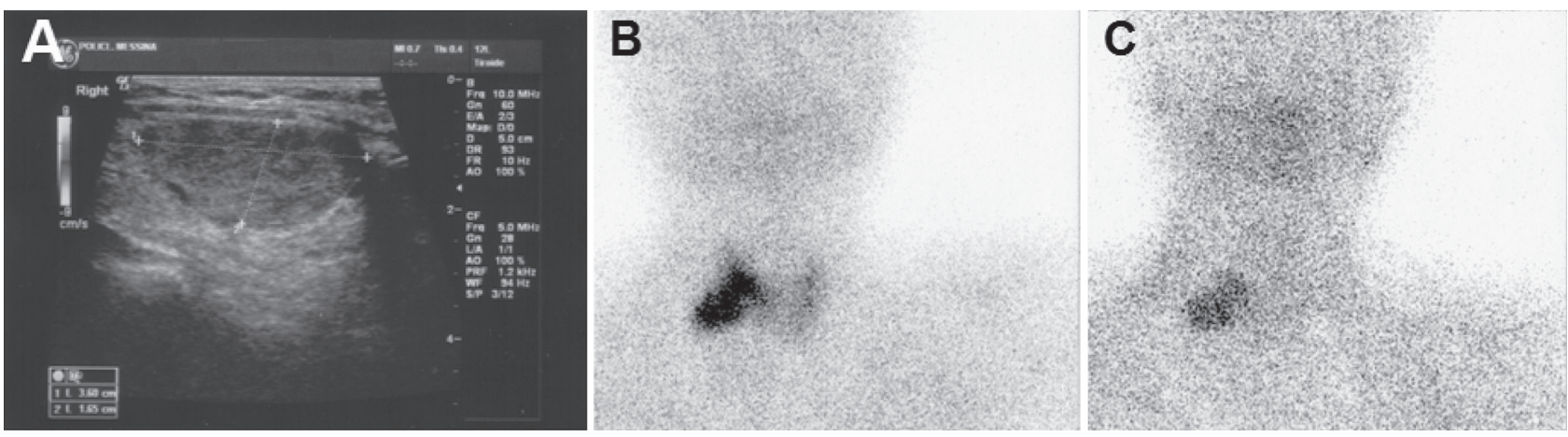

Figure 4. Case \#3. Neck ultrasonography, demonstrating an inhomogeneous, hypoechoic nodule of 36 mm in maximum diameter in the lower portion of the right thyroid lobe (A). Dual-phase ${ }^{99 \mathrm{~m}}$ Tc-MIBI scintigraphy revealed a single focus of sestamibi abnormal and non-homogenous uptake in the inferior right location $(\mathrm{B}, \mathrm{C})$.

and bone pain. Hypertension was treated with calcium channel antagonists. Six months before our observation, a renal colic occurred. During the same period, the patient complained of muscle weakness, fatigue, nausea, anorexia, dysphagia and severe weight loss $(10$ $\mathrm{kg}$ in a few weeks). Since these symptoms worsened, the patient was hospitalized. On physical examination, she was dehydrated and emaciated. Imaging studies (abdominal ultrasound, plain X-ray and CT) demonstrated the presence of right ureteral stones causing hydronephrosis, along with asymptomatic left renal pelvis stones. Esophago-gastroduodenal endoscopy demonstrated a reflux-induced esophagitis and erosive duodenitis, so that therapy with proton pump inhibitors and mucosal protecting drugs was started. As summarized in Table 1, laboratory tests disclosed modest chronic renal insufficiency and hypercalcemia $(15.3 \mathrm{mg} / \mathrm{dl}$; ionized calcemia $=1.9$ $\mathrm{mmol} / \mathrm{l}$ ), which prompted PTH assay. Serum PTH was markedly increased (1266 pg/ml). Neck US displayed an enlarged right thyroid lobe and an inhomogeneous, hypoechoic nodule of $36 \mathrm{~mm}$ in maximum diameter in the lower portion of the lobe, deforming the glandular profile (Figure 4, panel A). The nodule was hypervascularized on color Doppler, with abnormal peri- and intranodular blood flow. Parathyroid planar ${ }^{99 \mathrm{~m}} \mathrm{Tc}$-MIBI scintigraphy revealed a single focus of sestamibi accumulation in the inferior right location (Figure 4, panels B and C), and the patient was referred for surgery.

At neck exploration, an entirely intrathyroidal enlarged parathyroid gland was found and removed, 
along with the right thyroid lobe and paratracheal lymphatic compartment and soft tissues. At pathological examination a diagnosis of PC was made (Table 2). The MIB-1 immunostaining was evident in less than 5\% of neoplastic cells (mean Ki-67 LI 3.09). The mean NORA value was $4.735 \mu \mathrm{m}^{2}$ (Standard Error 0.201) (Table 2). Postoperatively, the patient developed symptomatic hypocalcemia that responded to temporary calcium supplementation. PTH levels dropped to $56.4 \mathrm{pg} / \mathrm{ml}$. Neck US, ${ }^{99 \mathrm{~m} T c-M I B I}$ scintigraphy and CT total body scan, performed three months after surgery, were negative for persistent/ recurrent disease. At 18 months follow-up, the patient was symptoms-free and serum calcium and PTH levels (monitored every three months) remained within normal values.

\section{DISCUSSION}

$\mathrm{PC}$ is a rare malignancy, with about 800 cases reported worldwide..$^{1-6}$ As mentioned above, it is found in about $1 \%$ of patients with primary hyperparathyroidism..$^{1-3}$ A relatively higher prevalence was reported in Italy and Japan where PC was diagnosed in up to $5 \%$ of patients operated on for primary hyperparathyroidism. ${ }^{11-13}$

$\mathrm{PC}$ is often difficult to diagnose preoperatively. The diagnosis is suggested by a combination of clinical and biochemical features, mainly markedly raised serum calcium levels (usually $>14 \mathrm{mg} / \mathrm{dl}$ ) and PTH. In addition, a palpable neck mass, which is unusual in parathyroid adenomas, has been reported in 30-76\% of patients with PC. ${ }^{1-3,14}$ The kidney and skeleton are the sites most affected by PC-associated hyperparathyroidism, and their involvement is more frequent and more severe than in benign lesions. ${ }^{1-3,12,13}$ Recurrent severe pancreatitis, peptic ulcer disease, anemia and psychiatric symptoms occur with greater frequency in patients with malignant disease than in those with benign primary hyperparathyroidism.

We have previously reported an uncommon case of PC presenting as normocalcemic hyperparathyroidism, with asthenia and mental depression being the sole symptoms reported by the patient along with DEXA evidence of osteoporosis..$^{15}$ The three cases reported herein highlight further the variability in clinical presentation of PC and the consequent dif- ficulties in diagnosing it pre-operatively.

In case \#1, PC-associated hyperparathyroidism was incidentally discovered during a biochemical follow-up after near-total thyroidectomy for a benign goiter. The patient had modestly elevated calcemia and frankly elevated PTH. A mild, asymptomatic case of osteoporosis was the sole alteration noted.

At the other extreme, the 20-yrs older case \#3 displayed almost all the clinically and biochemically distinct features of PC. The patient presented with severe hypercalcemia associated with related symptoms and signs (fatigue, weakness, weight loss, anorexia, nausea, vomiting, anemia, mental depression, renal colic and bone pain), and serum PTH levels were extremely high. Thus, malignancy was suspected pre-operatively and confirmed upon careful examination by pathologists. The peculiarity of this case is the fact that the parathyroid mass was entirely within the thyroid gland and invading the surrounding parenchyma. The intrathyroid location is one of the ectopic positions of the parathyroids. It is quite unusual that these intrathyroidal glands can develop into hyperfunctioning adenomas. ${ }^{16}$ To the best of our knowledge, only four other patients with intrathyroidal PC have been described in the literature. ${ }^{17-20}$

In case \#2, a diagnosis of primary hyperparathyroidism was made by endocrinologists on the basis of the skeletal involvement (bone pain, severe osteroporosis and multiple vertebral fractures), but clinical and biochemical data did not allow differentiation between cancer-associated hyperparathyroidism and the much more common benign counterpart. Malignancy was suspected at surgical exploration and confirmed at pathological examination.

At surgical exploration, $\mathrm{PC}$ typically presents as a lobulated, stony-hard mass surrounded by a fibrous, grayish-white capsule that adheres tenaciously to adjacent tissues. ${ }^{1,2}$ These operative findings may be helpful for decision-making during parathyroid surgery. The diagnosis of $\mathrm{PC}$, suggested intraoperatively by the abovementioned findings, should be confirmed at histopathological examination in accordance with the World Health Organization (WHO) criteria. ${ }^{21}$ These include the presence of vascular invasion, perineural space invasion, capsular penetration and/ 
or metastases. ${ }^{21}$ However, the histopathological distinction between benign and malignant parathyroid tumours is often difficult, with up to $50 \%$ of patients presenting metastases having been initially diagnosed with benign disease. ${ }^{3,9}$ Some morphological parameters that have been considered as signs of malignancy, such as presence of thick fibrous bands within the tumour, nuclear atypia and mitotic count, ${ }^{21-23}$ are present in only half of the cases of PC and may also be observed in adenomas. ${ }^{22}$ Several immunohistochemical markers, as parafibromin, retinoblastoma protein $(\mathrm{pRb}), \mathrm{p} 53$ and cyclin D1, have been sought for the recognition of parathyroid malignancy, but none of them appears to be specific and sensitive enough..$^{24-29}$ The proliferation marker Ki-67 has also been suggested as an adjunct tool, since PC generally have a more intense immunostaining for Ki-67 than adenomas. ${ }^{27-29}$ Although an overlap between benign and malignant parathyroid lesions exists, ${ }^{27}$ the current WHO guidelines on PC suggest that tumours with Ki-67 counts greater than $5 \%$ should be subject to closer follow-up due to an increased risk of malignancy. ${ }^{21}$

In our three cases, despite unequivocal histopathological features of malignancy (i.e., vascular and/or adjacent soft tissues' invasion, and/or lymph node metastases), the mean Ki-67 LI was never over 5\%, thus confirming how challenging is the diagnosis of PC. On the other hand, NORA values were high (ranging from $4.287 \mu \mathrm{m}^{2}$ to $4.735 \mu \mathrm{m}^{2}$ ), indicating an elevated proliferation rate. Indeed, AgNOR analysis may be helpful in distinguishing PC from adenoma. ${ }^{10,22,30,31}$ Tuccari et $\mathrm{al}^{10}$ showed that NORA values assist in distinguishing hyperplastic, adenomatous and cancerous parathyroid lesions because the corresponding mean \pm SE NORA values were $2.895 \pm 0.171$, $3.638 \pm 0.125$ and $4.701 \pm 0.179 \mu \mathrm{m} .{ }^{2}$ Furthermore, all the highest values pertained to metastatic PC. ${ }^{10}$ The NORA values encountered in the patients reported here and in the patient described elsewhere (4.972 $\left.\mu \mathrm{m}^{2}\right)^{15}$ agree with these previous data. ${ }^{10}$ Therefore, AgNORs may be regarded as a valuable aiding tool when the pathologist encounters difficulties in defining parathyroid tumours which are not clearly benign.

In conclusion, the present report on three cases of PC confirms to what extent it is still a challenge to differentiate between cancer-associated hyperparathyroidism and the much more common benign counterpart. As better outcomes are associated with complete resection of the tumour at the time of initial surgery, it is of great importance that $\mathrm{PC}$ be considered in the differential diagnosis of primary hyperparathyroidism. Finally, AgNOR analysis has additional value for the pathologist in complementing the routine histological evaluation of a parathyroid mass.

\section{None of the authors had any personal or financial conflicts of interest.}

\section{REFERENCES}

1. Shane E, 2001 Clinical review 122: Parathyroid carcinoma. J Clin Endocrinol Metab 86: 485-493.

2. Mittendorf EA, McHenry CR, 2005 Parathyroid carcinoma. J Surg Oncol 89: 136-142.

3. Marcocci C, Cetani F, Rubin MR, Silverberg SJ, Pinchera A, Bilezikian JP, 2008 Parathyroid carcinoma. J Bone Min Res 23: 1868-1880.

4. Hundahl SA, Fleming ID, Fremgen AM, Menck HR, 1999 Two hundred eighty-six cases of parathyroid carcinoma treated in the U.S. between 1985-1995: a National Cancer Data Base Report. The American College of Surgeons Commission on Cancer and the American Cancer Society. Cancer 86: 538-544.

5. Witteveen JE, Haak HR, Kievit J, Morreau H, Romijn JA, Hamdy NA, 2010 Challenges and Pitfalls in the Management of Parathyroid Carcinoma: 17-Year Follow-Up of a Case and Review of the Literature. Horm Cancer 1: 205-214.

6. Talat N, Schulte KM, 2010 Clinical Presentation, Staging and Long-Term Evolution of Parathyroid Cancer. Ann Surg Oncol 17: 2156-2174.

7. Fernandez-Ranvier GG, Khanafshar E, Jensen K, et al, 2007 Parathyroid carcinoma, atypical parathyroid adenoma, or parathyromatosis? Cancer 110: 255-264.

8. Sundelin K, Tullgren O, Farnebo LO, 1994 Clinical course of metastatic parathyroid cancer. World J Surg 18: 594-598.

9. Koea JB, Shaw JH, 1999 Parathyroid cancer: Biology and management. Surg Onc 8: 155-165.

10. Tuccari G, Abbona GC, Giuffrè G, et al, 2000 AgNOR quantity as a prognostic tool in hyperplastic and neoplastic parathyroid glands. Virchows Arch 437: 298-303.

11. Favia G, Lumachi F, Polistina F, D’Amico DF, 1998 Parathyroid carcinoma: sixteen new cases and suggestions for correct management. World J Surg 22: 1225-1230.

12. Obara T, Fujimoto Y, 1991 Diagnosis and treatment of patients with parathyroid carcinoma: an update and review. World J Surg 15: 738-744.

13. Obara T, Okamoto T, Kanbe M, Iihara M, 1997 Functioning parathyroid carcinoma: clinicopathologic features and rational treatment. Semin Surg Oncol 13: 134-141. 
14. Levin KE, Galante M, Clark OH, 1987 Parathyroid carcinoma versus parathyroid adenoma in patients with profound hypercalcemia. Surgery 101: 649-660.

15. Campennì A, Ruggeri RM, Sindoni A, et al, 2012 Parathyroid carcinoma presenting as normocalcemic hyperparathyroidism. J Bone Mineral Metab 30: 367-372.

16. Wheeler MH, Williams ED, Wade JSH, 1987 The hyperfunctioning intrathyroidal parathyroid gland: A potential pitfall in parathyroid surgery. World J Surg 11: 110-114.

17. Crescenzo DG, Shabahnag M, Garvin, Evans SRT, 1998 Intrathyroidal Parathyroid Cancer Presenting as a Left Neck Mass. Thyroid 8: 597-599.

18. Schmidt JL, Perry RC, Philippsen LP, Wu HH, 2002 Intrathyroidal parathyroid carcinoma presenting with only hypercalcemia. Otolaryngol Head Neck Surg 127: 352-353.

19. Foppiani L, Del Monte P, Sartini G, et al, 2007 Intrathyroidal parathyroid carcinoma as cause of hypercalcemia and pitfall of localization techniques: clinical and biologic features. Endocr Pract 13: 176-181.

20. Kruljac I, Pavic I, Matesa N, et al, 2011 Intrathyroid parathyroid carcinoma with intrathyroidal metastasis to the contralateral lobe: source of diagnostic and treatment pitfalls. Jpn J Clin Oncol 41: 1142-1146.

21. DeLellis RA 2006 Parathyroid carcinoma. In: R.A. DeLellis, R.V. Lloyd, P.U. Heitz, and C. Eng, Eds. World Health Organization Classification of Tumours. Pathology and Genetics of Tumours of Endocrine Organs. IARC Press, Lyon, France.

22. Schantz A, Castleman B, 1973 Parathyroid carcinoma: a study of 70 cases. Cancer 31: 600-605.

23. Bondeson L, Sandelin K, Grimelius L, 1993 Histopathological variables and DNA cytometry in parathyroid carcinoma. Am J Surgical Pathol 17: 820-829.

24. Juhlin CC, Villablanca A, Sandelin K, et al, 2007 Parafibromin immunoreactivity: Its use as an additional diagnostic marker for parathyroid tumor classification. Endocr Relat Cancer 14: 501-512.

25. Kayath MJ, Martin LC, Vieira JGH, Roman LM, Nos'eAlberti V, 1998 A comparative study of p53 immunoexpression in parathyroid hyperplasias secondary to uremia, primary hyperplasias, adenomas and carcinomas. Eur J Endocrinology 139: 78-83.

26. Vasef MA, Brynes RK, Sturm M, Bromley C, Robinson RA, 1999 Expression of cyclin D1 in parathyroid carcinomas, adenomas, and hyperplasias: a paraffin immunohistochemical study. Mod Pathol 12: 412-416.

27. Abbona GC, Papotti M, Gasparri G, Bussolati G, 1995 Proliferative activity in parathyroid tumors as detected by Ki-67 immunostaining. Hum Pathol 26: 135-138.

28. Lloyd RV, Carney JA, Ferreiro JA, et al, 1995 Immunohistochemical analysis of the cell cycle-associated antigens $\mathrm{Ki}-67$ and retinoblastoma protein in parathyroid carcinomas and adenomas. Endocrine Pathol 6:279-287.

29. Farnebo F, Auer G, Farnebo LO, et al, 1999 Evaluation of retinoblastoma and $\mathrm{Ki}-67$ immunostaining as diagnostic markers of benign and malignant parathyroid disease. World J Surgery 23: 68-74.

30. Boquist LL, 1990 Nucleolar organizer regions in normal, hyperplastic and neoplastic parathyroid glands. Virchows Arch A Pathol Anat Histopathol 417: 237-241.

31. Kanematsu E, Matsui H, Deguchi T, et al, 1997 Significance of AgNOR counts for distinguishing carcinoma from adenoma and hyperplasia in parathyroid gland. Hum Pathol 28: 421-427. 